\title{
Effects of bromadiolone poisoning on the central nervous system
}

\author{
This article was published in the following Dove Press journal: \\ Neuropsychiatric Disease and Treatment \\ 30 August 2017 \\ Number of times this article has been viewed
}

\section{Meiling Wang \\ Yanfeng Yang ${ }^{2}$ \\ Yiwei Hou' \\ Wenbin $\mathrm{Ma}^{\prime}$ \\ Rui Jia' \\ Jinbo Chen'}

'Neurology Department, Binzhou Medical University Hospital, Binzhou Medical University, ${ }^{2}$ Binzhou Blood

Center, Binzhou, China
Correspondence: Jinbo Chen Neurology Department, Binzhou Medical University Hospital, Binzhou Medical University, Yellow River Road 66I, Binzhou 256603, China

Tel +86 I86 543। I6II

Email chenjinbo6720@126.com

\begin{abstract}
Cases of rodenticide poisoning (second-generation long-acting dicoumarin rodenticide, superwarfarin) have occasionally been reported. The main symptoms of bromadiolone poisoning are skin mucosa hemorrhage, digestive tract hemorrhage, and hematuresis. However, the symptoms of central nervous system toxicity have rarely been reported. Our case reports on a 41-year-old male who had no contact with bromadiolone. His main symptoms were dizziness, unsteady gait, and abnormal behavior. Laboratory test results revealed the presence of bromadiolone in his blood and urine, a longer prothrombin time, activated partial thromboplastin time, and a high international normalized ratio. Magnetic resonance imaging of the brain showed that the bilateral posterior limb of the internal capsule, splenium of corporis callosum, and bilateral centrum semiovale formed symmetrical patch distribution. The patient gradually recovered after treated with vitamin K1 and plasma transfusion. Our clinical study could pave the way to improve the detection of bromadiolone poisoning and avoid misdiagnosis.
\end{abstract}

Keywords: bromadiolone, poisoning, central nervous system, superwarfarin

\section{Introduction}

Bromadiolone, a widely available superwarfarin, is a second-generation long-acting dicoumarin rodenticide. In the mid-1970s, superwarfarin was the most widely used rodenticide worldwide. Unfortunately, cases of poisoning increased with the increasing usage of this compound. As reported in Turkey, Croatia, Taiwan, China, Australia, Argentina, and America, superwarfarin poisoning is a worldwide health problem. ${ }^{1-7}$ In recent years, cases of rodenticide poisoning were occasionally reported in China with symptoms including skin mucosa hemorrhage, digestive tract hemorrhage, and hematuresis. However, damage to the central nervous system (CNS) has rarely been reported. We report on a case of bromadiolone poisoning treated at our hospital.

\section{The case}

A 41-year-old male driver was hospitalized on May 28, 2016, because of dizziness, unsteady gait, and abnormal behavior. Two days before admission, the patient experienced dizziness, eyeball rotation with blindness, unsteady gait, absence of headache, nausea, and an instance of emesis. However, the patient disregarded the symptoms and did not initially seek medical help.

One day before admission to our hospital his symptoms worsened, and a manifestation of alalia occurred. He was sent to a local hospital, and on the way to hospital, the patient demonstrated irrational fear of smooth driving, although no visible abnormality was observed in a brain computed tomography (CT) scan. The patient was 
treated (medicine and dosage unknown), and in the meantime he occasionally could communicate to others with simple words.

Nine hours before admission to our hospital, the patient exhibited sudden dysphoria. After an intravenous injection of diazepam, symptoms of dysphoria were alleviated. For further treatment he was sent to our hospital (Binzhou Medical University Hospital, Binzhou, China), and admitted to the Emergency Department because of his psychological and behavioral abnormalities. No visible abnormality was observed after reexamination of his brain CT.

In the past week before admission to our hospital, the patient experienced dizziness once. Physical examination results showed symptoms of confusion, dysphoria, and alalia. A detailed physical examination observed dicoria, sensitivity to light, shallow right nasolabial groove, body mobility, bilateral Babinski (-), disobliging during coordinated movement assessment, and soft neck.

After admission, the patient still presented dysphoria, was uncommunicative with his family, could not write, had dysdipsia, and was salivating. However, signs of cognition were still present given that he could understand his family.

Magnetic resonance imaging (MRI) of the brain (Figure 1) shows the following: bilateral posterior limb of internal capsule, splenium of corporis callosum, and bilateral centrum semiovale that formed symmetrical patch distribution; abnormal signals of long $\mathrm{T} 1$ and $\mathrm{T} 2$, high signal of fluid-attenuated inversion recovery (FLAIR), and diffusionweighted imaging (DWI).

Admission test results (May 28, 2016) were as follows: prothrombin time (PT), $100.0 \mathrm{~s}$; activated partial thromboplastin time (APTT), $60.50 \mathrm{~s}$; international normalized ratio (INR), 8.62. The liver function, renal function, blood routine, and electrolyte were normal.

Considering the possibility of brain intoxication, the hospital performed a poison detection test, and results indicated the presence of bromadiolone $(239 \mathrm{ng} / \mathrm{mL})$.

Regarding abnormal blood coagulation mechanism, the patient was diagnosed with brain intoxication (bromadiolone poisoning) and treated with vitamin $\mathrm{K} 1$ and blood plasma.

Reexamination (June 1, 2016) results showed: PT, 18.4 s; APTT, $42.90 \mathrm{~s}$; INR, 1.65; relief from confusion and dysphoria.

Written informed consent has been provided by the patient to have these case details and any accompanying images published.

\section{Discussion}

Bromadiolone is a strong and long-acting rodenticide. The compound is called superwarfarin because of its high potency and long-acting anticoagulation, which depends on vitamin $\mathrm{K}$ in the body. Reports show that superwarfarin is 100 times more effective than warfarin. ${ }^{8}$ Given its long half-life, the liver detoxifies slowly because of warfarin's lipophilic property. ${ }^{9,10}$ Bromadiolone's maximum half-life period is 56 days (mean 20-30 days). ${ }^{7,11}$ Due to its high lipid solubility, bromadiolone might easily diffuse across the blood-brain barrier and, therefore, cause CNS toxicity. Blood-brain barrier models could be helpful to investigate its putative brain penetration.

The chemical decreases blood coagulation factors (II, VII, IX, X) of vitamin K-dependent proteins by inhibiting vitamin $\mathrm{K}$ epoxide reductase, which plays a role in anticoagulation. Clinical manifestations are tissue and organ hemorrhages, such as skin mucosa hemorrhage, digestive tract hemorrhage, and hematuresis. Laboratory examination shows prolonged PT and APTT and rising INR for bromadiolone poisoning. Vitamin K-dependent proteins not only function in coagulation but also in the CNS, where they are involved in maintaining normal brain cells and homeostasis. ${ }^{12,13}$ Glutamine carboxylase plays an important role in neurons and neuroglia cells. In the CNS, a lack of vitamin K may decrease the activities of glutamine carboxylase and carboxylases of protein in the brain, resulting in reduced synthesis of sulfatide, which is an important inherent structure of medullary sheath. Warfarin has been proven to reduce rodent cerebroside sulfate $(>40 \%)$; this effect can be reversed by vitamin $\mathrm{K}$ treatment. ${ }^{14}$ This research shows that superwarfarin can cause lesions in the CNS.

Our case is rare in clinical settings. The patient did not present any hemorrhage symptoms in the tissues and organs such as digestive tract, urinary system, or skin mucosa. The patients symptoms included dizziness, alalia, dysdipsia, inability to write, unsteady gait, sense of fear, dysphoria, and nervous system symptoms. An MRI of the brain revealed the following: signals of long T1 and T2 and high signal of FLAIR and DWI in bilateral pons of brachium conjunctivum, basal ganglia region, splenium of corpus callosum, and corona radiata region, revealing multiple protein lesions. Coagulation index indicated prolonged PT and APTT and rising INR. Bromadiolone was detected in the blood. Thus, the abovementioned symptoms may cause lesions of the nervous system. Vitamin K1 is an effective antidote to bromadiolone poisoning. After treatment with vitamin K1 and plasma 

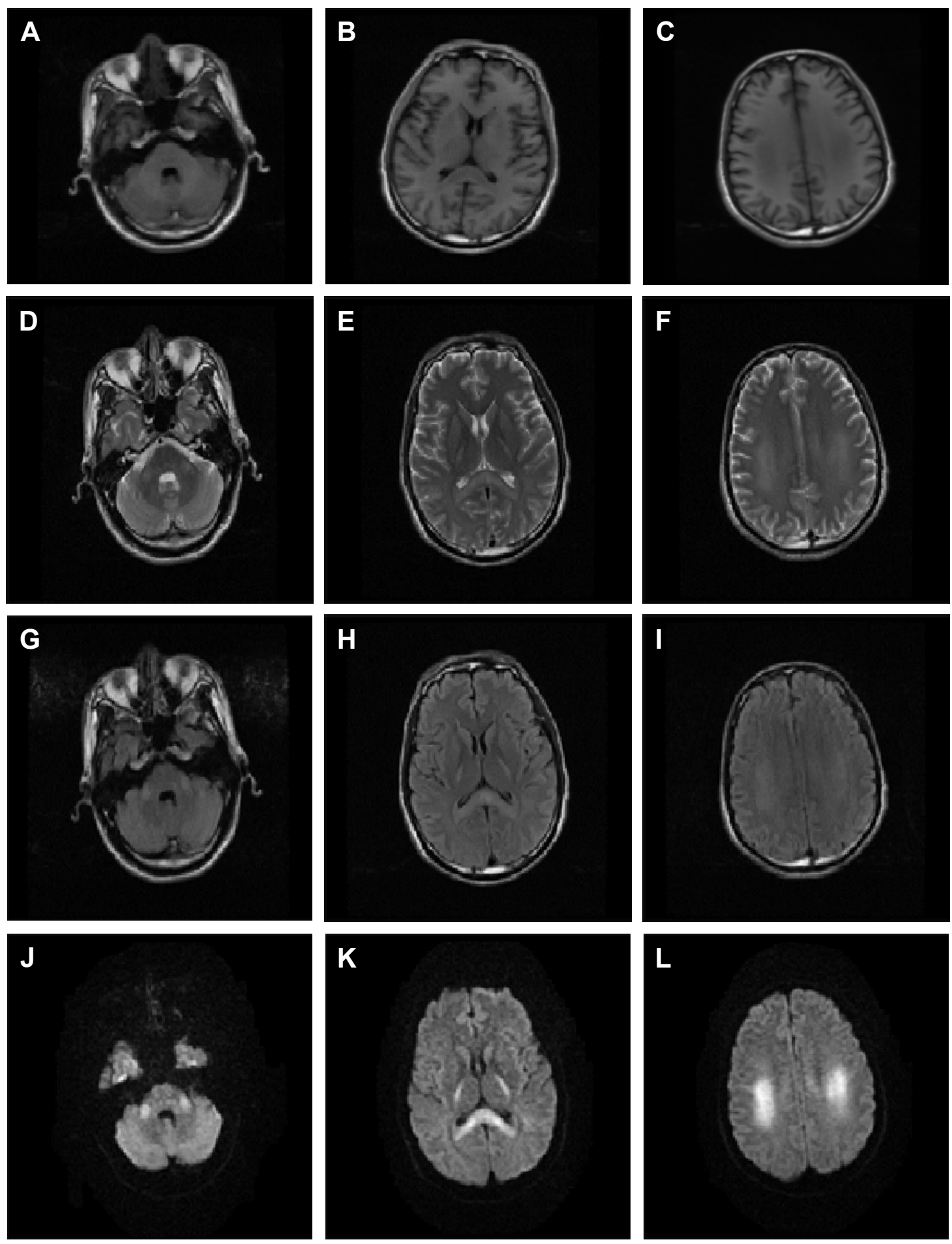

Figure I Brain MRI results: bilateral posterior limb of internal capsule, splenium of corporis callosum, and bilateral centrum semiovale that formed symmetrical patch distribution.

Note: Abnormal signals of long TI (A-C) and T2 (D-F) and high signal of FLAIR (G-I) and DWI (J-L) were also noted.

Abbreviations: DWI, diffusion-weighted imaging; FLAIR, fluid-attenuated inversion recovery; MRI, magnetic resonance imaging.

transfusion to supply coagulation factors, the patient's PT, APTT and INR indexes presented good results. The patient needed long-term treatment of vitamin $\mathrm{K} 1$ because of the long half-life period of bromadiolone.

\section{Conclusion}

Bromadiolone poisoning should be diagnosed and treated as early as possible. Misdiagnoses can easily incur because some patients cannot identify their contact history with 
bromadiolone, or clinical symptoms are atypical. For patients with atypical clinical symptoms, including the absence of hemorrhage and abnormal coagulation indexes, the possibility of bromadiolone poisoning should be considered. Thus, chemical poisons should be detected as early as possible with early diagnosis and treatment.

\section{Conclusion}

Clinical symptoms, laboratory examinations, and a brain MRI revealed that bromadiolone poisoning might cause lesions in the CNS. Vitamin K1 and plasma transfusion are an effective treatment. This disease should be detected as early as possible with early diagnosis and treatment.

\section{Acknowledgments}

Our thanks to the patient who is mentioned in this case report and his family. This work has been strongly supported by the Neurology Department of Binzhou Medical University, Benzhou, China.

\section{Disclosure}

The authors report no conflicts of interest in this work.

\section{References}

1. Altay S, Cakmak HA, Boz GC, et al. Prolonged coagulopathy related to coumarin rodenticide in a young patient: superwarfarin poisoning. Cardiovasc J Afr. 2012;23(9):e9-e11.
2. Rutovic S, Dikanovic M, Mirkovic I, et al. Intracerebellar hemorrhage caused by superwarfarin poisoning. Neurol Sci. 2013;34(11): 2071-2072.

3. Yu HY, Lin JL, Fu JF, et al. Outcomes of patients with rodenticide poisoning at a far east poison center. Springerplus. 2013;2:505.

4. Fang Y, Ye D, Tu C, et al. Superwarfarin rodent poisons and hemorrhagic disease. Epidemiology. 2012;23(6):932-934.

5. Gunja N, Coggins A, Bidny S. Management of intentional superwarfarin poisoning with long-term vitamin $\mathrm{K}$ and brodifacoum levels. Clin Toxicol (Phila). 2011;49(5):385-390.

6. Rauch AE, Weininger R, Pasquale D, et al. Superwarfarin poisoning: a significant public health problem. J Community Health. 1994; 19(1):55-65.

7. Olmos V, Lopez CM. Brodifacoum poisoning with toxicokinetic data. Clin Toxicol (Phila). 2007;45(5):487-489.

8. Garrett SB, Perceus ZM. Brodifacoum inhalation and its clinical manifestations in a 21-year-old Caucasian man. Lab Med. 2016;47(1):63-66.

9. Card DJ, Francis S, Deuchande K, Harrington DJ. Superwarfarin poisoning and its management. BMJ Case Rep. 2014;2014.

10. Redfern R, Gill JE, Hadler MR. The evaluation of WBA 8119 as a rodenticide for use against warfarin-resistant and non-resistant rats and mice. J Hyg (Lond). 1976;77:419-426.

11. Pavlu J, Harrington DJ, Voong K, et al. Superwarfarin poisoning. Lancet. 2005;365(9459):628.

12. Feinstein DL, Akpa BS, Ayee MA, et al. The emerging threat of superwarfarins: history, detection, mechanisms, and countermeasures. Ann N Y Acad Sci. 2016;1374(1):111-122.

13. Ferland G. Vitamin K and the nervous system: an overview of its actions. Adv Nutr. 2012;3(2):204-212.

14. Sundaram KS, Lev M. Warfarin administration reduces synthesis of sulfatides and other sphingolipids in mouse brain. J Lipid Res. 1988; 29(11):1475-1479.
Neuropsychiatric Disease and Treatment

\section{Publish your work in this journal}

Neuropsychiatric Disease and Treatment is an international, peerreviewed journal of clinical therapeutics and pharmacology focusing on concise rapid reporting of clinical or pre-clinical studies on a range of neuropsychiatric and neurological disorders. This journal is indexed on PubMed Central, the 'PsycINFO' database and CAS,

\section{Dovepress}

and is the official journal of The International Neuropsychiatric Association (INA). The manuscript management system is completely online and includes a very quick and fair peer-review system, which is all easy to use. Visit http://www.dovepress.com/testimonials.php to read real quotes from published authors. 